\title{
INNOVATIVE APPROACHES AND INNOVATIONS IN RURAL DEVELOPMENT IN BULGARIA
}

\author{
Julia Doitchinova ${ }^{1}$, Zornitsa Stoyanova $^{2}$, Hristina Harizanova-Bartos ${ }^{3}$
}

\begin{abstract}
The LEADER approach has an important role for strengthening the development of local communities and for stimulating innovations and innovative practices in rural areas. The aim of this paper is to analyze and evaluate the LEADER approach as an innovative approach and on this basis to prepare general conclusions about the innovative development of rural areas in Bulgaria. The local active group (LAG) is interpreted as an innovative "coordinating" activity and it is the core of the innovation system that solves conflicts, and creates and implements local strategies for rural development. The LEADER and the Community - led local development approaches introduce innovative practices for Bulgarian conditions in order to improve local governance and facilitate innovations. The main contributions of the LEADER and the Community approaches are related to: the establishment of local active groups in different network structures of partnership; activating stakeholders, broadcasting leaders and improving coordination between them; establishing local expertise and administrative capacities; support for business organizations, local authorities and the non-governmental sector in the development and management of innovative projects. The factors that influence the success of the LEADER approach and its importance for rural development in each country differ in their administrative, socio-economic, historical and cultural contexts. Bulgarian LAGs continue to implement the Community - led local development approach (CLLDA) in the process of adapting to the specific conditions of rural areas.

The results are part of scientific project DN 15/8 2017 Sustainable multifunctional rural areas: reconsidering agricultural models and systems with increased demands and limited resources funded by the Bulgarian research fund.
\end{abstract}

JEL Classification Numbers: O31, R58, DOI: 10.12955/cbup.v7.1344

Keywords: LEADER, innovative approach, rural development

\section{Introduction}

The LEADER approach is an essential tool for strengthening the development of local communities. It plays an important role in stimulating new and innovative practices in rural areas. The Local active groups (LAGs) have broad boundaries of freedom and flexibility in decision making, which stimulates innovation in rural development.

The main problems with the establishment of LAGs as well with the initials strategies for local development in Bulgaria are made with the following presumptions: a limited or lack of expertise in the created groups, or underdeveloped structures and procedures for the implementation of LAGs (Doitchinova et al., 2012). In this study an analysis is conducted of the funding from Rural development program (RDP) in comparison to other countries in the EU (Doitchinova et al., 2015). Up to date of this study, the attempts to uncover the essential role of LAGs for the development of cooperation and the creation of new decision-making mechanisms within rural communities, as well as the acceleration of innovations and the improvement of the quality of life in rural areas are limited.

The aim of the paper is to analyze and evaluate the LEADER approach as an innovative approach and on this basis to prepare general conclusions about the innovative development of rural areas in Bulgaria.

\section{The innovations in rural areas}

Researchers of innovation in rural areas (Mahroum et al., 2007) define innovation as "the implementation of something new (new changes) in economic or social lives in rural areas". According to the authors' view the criteria for innovation is adding an economic or social value to rural life. On this basis, three types of innovation in rural areas are proposed: the transformation of innovations from one rural area through the implementation of the innovations in other areas; innovations in rural areas that appeared outside of the region; and innovations that are universal with a strong impact on rural life (e.g.: internet access). These three types of innovation are not likely to exist separately but often they are combined with market forces and a wider innovation system.

The implementation of the LEADER approach in rural areas includes the use of cooperation as a key factor in defining and implementing a regional development policy. In fact stakeholder collaboration in rural areas between official institutions, local partnerships, coalitions or informal organizations is a prerequisite for the definition by some authors of the "innovation system". The system is defined as "... a group of organizations and individuals involved in the generation,

\footnotetext{
${ }^{1}$ Business faculty, UNWE, juliadoj@abv.bg

${ }^{2}$ Business faculty, UNWE, zstoyanova@unwe.bg

${ }^{3}$ Business faculty, UNWE, h.harizanova@gmail.com
} 
dissemination, adaptation and use of socio-economic knowledge, and the institutional context that governs the way in which these interactions and processes take place" (Hall et al., 2004). Researchers perceive the wider meaning of innovation as an interactive process that includes interests of different natures and purposes. In this regard, the innovation system focuses on different spheres of social life, geographic and sectoral dimensions as well as a set of implemented activities. The concept of the innovation system provides a complex framework covering: "partnership models" - institutions (as main sources for managing these relationships and processes); elements (the social element in innovative enterprises); system capacity, the process of key interaction between a particular sector and science or as an expansion of science-based sectors (Hall et al., 2004). The innovation process provides significant results with positive social consequences and an increase in sustainable sectoral and regional growth as a result of the interaction of many diverse and complementary actions coordinated by different actors. Innovative "coordinating" activities aim to create connections between communities and economic actors. Innovative "structuring" activities are aimed at changing the material or intangible environment of the area to make it more favorable for the creation of activities. Innovative "consolidation" activities aim to consolidate economic activity in a variety of areas such as agro-food products, crafts, tourism, services etc. Therefore, these three types of innovative actions are interrelated and complement each other in rural development processes. On this basis opportunities are created for innovative rural development through cooperation, association and networking (Doitchinova \& Zaimova, 2015).

The development of the LEADER approach with the Community - led local development approach (CLLDA) (EC,2014) in the current programming period (2014-2020) is evaluated by some authors (Bumbalova et al., 2016; Aldorfai et al., 2016) as a flexible approach with greater incentives for the development of the rural areas.

\section{Methodological framework}

The analysis of the results of the implementation of the LEADER approach and the progress of the activity realization according the CLLDA is based on the use of primary data from the Ministry of Agriculture and Food and secondary data from reports and analyses of LAGs. Evaluations of innovative approaches and the implemented innovations in rural areas are based on a set of indicators in two rural development programs since 2007 and the observed progress.

The LAG is interpreted as an innovative "coordinating" activity and it is the core of the innovation system for conflict solving, and the creation and implementation of local development strategies. The strategies create conditions for rural development on the basis of cooperation and innovation. In this context, the activities of acquiring skills and achieving social activity, creating expert and administrative capacity, managing the implementation of local development strategies are assessed.

Experts' opinions from four regional directorates of agriculture in Shumen, Varna, Blagoevgrad and Kyustendil are used for the evaluation of the role of the LEADER approach for rural development and the nature of innovation. The role of LAGs to improve the business environment and the living conditions of rural residents is evaluated through the five-step Likert scale.

\section{The LEADER approach as an innovative approach over the last decade in Bulgaria}

The LEADER approach was implemented for the first time in Bulgaria over the 2007-2013 program period. The program aims to distinguish regional features and problems, to motivate and integrate the local community (non-governmental sector, entrepreneurs and local municipalities) (Dax et al., 2016; Miller, 2014; Svoboda, 2015) to identify the local needs according to local potential and inter-sectoral cooperation. This implies a substantial transition from traditional policy (a top-down approach mainly used in the development of larger centers) and sectoral and industrial development (Pike et al., 2006) to a bottom-up approach and cooperation between the public and private sectors where the third sector becomes a significant force in shaping and changing society (Prits et al., 2016) and allows the inclusion of social capital (Kis, 2012). This is an innovative approach for Bulgaria's rural areas.

The limited preliminary experience and the lack of capacity are among the main reasons for the funding limitation to $2.6 \%$ of the total Rural development program funds (close to the minimum threshold of $2.5 \%$ Regulation (EC) No 1698/2005), hence the importance of the LEADER approach. In the process for the implementation of the RDP, after 16 changes and a substantial redistribution of funds, the Axis 4 was reduced to $1.8 \%$ of the total funds. Axis 4 funding was reduced by $30.7 \%$ in the final budget. The largest decrease in budgets is for Measure 421 Inter-territorial and trans-national cooperation (93.4\%). 
The decrease for measure 41 Implementation of local development strategies is $26.2 \%$. The prevailing part of the expenditures of Axis 4 (over 74\%) is focused on implementing local development strategies. The two dominant measures are 413 and 431, with final expenditures that amount to $53.18 \%$ and $25.16 \%$ respectively of the actual costs incurred. The cooperative measure 421 accounts for the lowest costs only $0.58 \%$ of the axis and measure $412-0.96 \%$, which reflect the low priority given to cooperation and the environment under the LEADER program.

The creation of the local innovation system in Bulgarian rural areas is also constrained by the reduction of the planned measure 341 Acquisition of skills and achievement of social activity in accordance to the preparation and implementation of local development strategies with financial resources amounting to EUR 61.437 million.

Innovative coordination and structuring activities of stakeholders are related to the creation of an expert and administrative capacity. Capacity is created for the consolidation activities as a result of the project's realization through the LAGs and these kind of activities support actions in different economical areas.

The creation of administrative capacity, supported by sub-measure 431-2 Acquisition of skills and achievement of public activity in the territories for potential local action groups in rural areas stimulates a significant interest. The candidates for funding number 136 from 181 rural municipalities. This means that $78 \%$ of rural municipalities have established LAGs as public-private partnerships between the public sector, businesses and non-governmental organizations. As a result of the selection process 102 contracts with potential LAGs were concluded and 90 contracts were realized. 137 municipalities (60\% of the total number of municipalities in rural areas in Bulgaria) have created local development strategies. 35 LAGs or $38.9 \%$ of the 90 LAGs that have local development strategies covering 57 municipalities ( $28 \%$ of rural areas) have the financial capacity to implement local development strategies.

The analysis shows that the target set for a number of assisted LAGs is 70\% (35 from 50 planned) and with regard to the indicator related to the total area covered by the LAG, the result is $72 \%$ (25 800 sq.m. from 36000 sq.m. planned). The LAGs use as an indicator for success - the population size. The result connected to the indicator population covered by the LAG is $64 \%$ (801 688 persons achieved from 1 260000 persons).

Real administrative capacities were created in the supported LAGs and 151 job positions in four categories were opened - executive director, technical assistant, expert and accountant.

An innovative approach was used in several territories. LAGs were included in measures for local development strategies that were not under Axis 4 but included in EU Regulation 1698/2005. This is the Measure 323 Preservation and Improvement of Rural Heritage and the Measure 331 Vocational training and information provision for economic actors operating in Axis 3 areas. Although a large budget is not allocated for measure 323, it is extremely important as it is aimed to support rural and natural heritage projects. Through this measure, activities for the popularization of cultural material and immaterial heritage - elaboration of films with cultural orientation, purchase of costumes for amateur groups, printing of books, organization of festivals and other activities that support the cultural identity and activity of the rural areas, are realized. Some good and innovative practices can be found in the Isperih LAG, where in addition to all other activities an own "designer" label was created.

The implementation of the LEADER approach through the creation of an innovation system was constrained by the non-observance of legally established deadlines for the implementation of the measures under the RDP, and the repeated changes in the regulations etc. (Doitchinova and Stoyanova, 2014). This is the reason for the extension of deadlines in all stages of the LAG, the annexes for the transfer of funds from measure to measure in local development strategies, team member changes, changes in indicators, budget changes, etc. The delay in approving local development strategies for the procedure - the approval of the contracts for financing the strategies, the negotiation of the projects of the candidates, the approval of the planned costs and activities (the annual budget of the strategy is more than 18 months after the end of the projects supported by the preparatory measure). This was the cause for the high turnover in the LAG teams. For the period 2012-2014, 68\% of the executive directors, $70 \%$ of the experts, $59 \%$ of the accountants and $72 \%$ of the technical assistants left their job. The delay in funding has also led to the failure in the expenditure planning as a result of a persistent financial deficit in the LAG. 
The implementation of the CLLDA with multi-fund financing has created a basis for significantly better targeting of public funds for the needs of individual rural areas. The exit from the RDP framework and the creation of opportunities for funding from the Operational Program "Human Resources Development", Operational Program "Environment", OP "Science and Education for Smart Growth", and OP "Innovation and Competitiveness" was a favorable opportunity for the realization of significantly more important projects.

The information according the possible maximum funding for all five programs (Table 1) shows that the total amount per strategy can be up to 4.46 million euro which is 2.23 times more than the previous period. This is one of the reasons for raising the interest of the rural population to the program.

\begin{tabular}{||l|l|l|}
\hline \multicolumn{2}{|c|}{ Table 1:Requirements and maximum funding for a local development strategy } \\
\hline \multicolumn{1}{|c|}{ Programs } & \multicolumn{1}{c|}{ Requirements } & \multicolumn{1}{c|}{ Maximum funding } \\
\hline Rural Development Program & below 10000 inhabitants & 1 million EUR \\
& over 15000 inhabitants & 1.5 million EUR \\
\hline OP"Human Resources Development" & & 0.76 million EUR \\
\hline OP"Innovation and Competitiveness" & $10000-15000$ inhabitants & 0.5 million EUR \\
& $15000-45000$ inhabitants & 1 million EUR \\
& over 15000 inhabitants & 1.5 million EUR \\
\hline OP"Science and Education for Smart Growth" & & 0.5 million EUR \\
\hline OP"Environment" & 60 euro/ha - Natura 2000 & 0.2 million EUR \\
\hline
\end{tabular}

Source: MAF, 2018

Within the framework of the two calls under Measure 19.2. - 63 local development strategies have been approved, which is $4.8 \%$ above the set-up indicators in the Rural Development Program (2014-2020) and a 55\% increase (compared with 2007-2013). These are the territories of 114 municipalities or 49\% of rural municipalities in Bulgaria (Table 2). Almost half of the LAGs are combined between 2 municipalities (49.3\%), followed by one municipality (34.9\%). Only $15.8 \%$ of LAGs combine territories of 3 municipalities.

The most numerous are the strategies that are funded by only one program (39.9\%), followed by those involving three programs (36.5\%). Only 4 strategies will be funded from the possible 5 programs, with LAGs dominated within a single municipality territory (Table 2).

Table 2: Distribution of LAGs according to the number of municipalities involved and the number of sources of funding for their local development strategies

\begin{tabular}{|c|c|c|c|c|c|}
\hline \multirow{2}{*}{$\begin{array}{c}\text { Local development } \\
\text { strategies funded } \\
\text { by the programms }\end{array}$} & \multicolumn{3}{|c|}{$\begin{array}{c}\text { Number of LAGs on } \\
\text { the territory }\end{array}$} & \multirow{2}{*}{ All } & \\
\cline { 2 - 5 } & 1 municipality & 2 municipalities & 3 municipalities & & \\
\hline 1 program & 8 & 14 & 3 & 25 & 39.9 \\
\hline 2 programs & 4 & 2 & - & 6 & 9.5 \\
\hline 3 programs & 5 & 12 & 6 & 23 & 36.5 \\
\hline 4 programs & 2 & 2 & 1 & 5 & 7.9 \\
\hline 5 programs & 3 & 1 & - & 63 & 6.2 \\
\hline All & 22 & 31 & 10.8 & 100 & 100 \\
\hline Structure (\%) & 34.9 & 49.3 & 30 & 114 & \\
\hline $\begin{array}{c}\text { Number of } \\
\text { municipalities }\end{array}$ & 22 & 62 & & & \\
\hline Source: MAF, 2018 & & & \\
\hline
\end{tabular}

The map presents the LAG territories that have approved local development strategies from 2017 and 2018. They are not evenly distributed on the countries' territory. Their presence is most significant in parts of the Northeastern, Southwestern, and Central located areas of the country. Development strategies are not implemented on the territory of two districts in Bulgaria - Vidin and Kyustendil. In four other areas in the Northwest and Southwest districts the CLLD approach is applied only in a few municipalities.

It can be summarized that during the first programming period the LEADER approach is assessed as innovative for the Bulgarian rural areas with the activation activities of the local communities, the creation of expert and administrative capacity and the coordination of the interests and priorities of the rural stakeholders. In the current (second for Bulgaria) period, the activities for creating strategies based 
on the multi-fund financing and project management under the RDP and the other four operational programs are assessed as innovative.

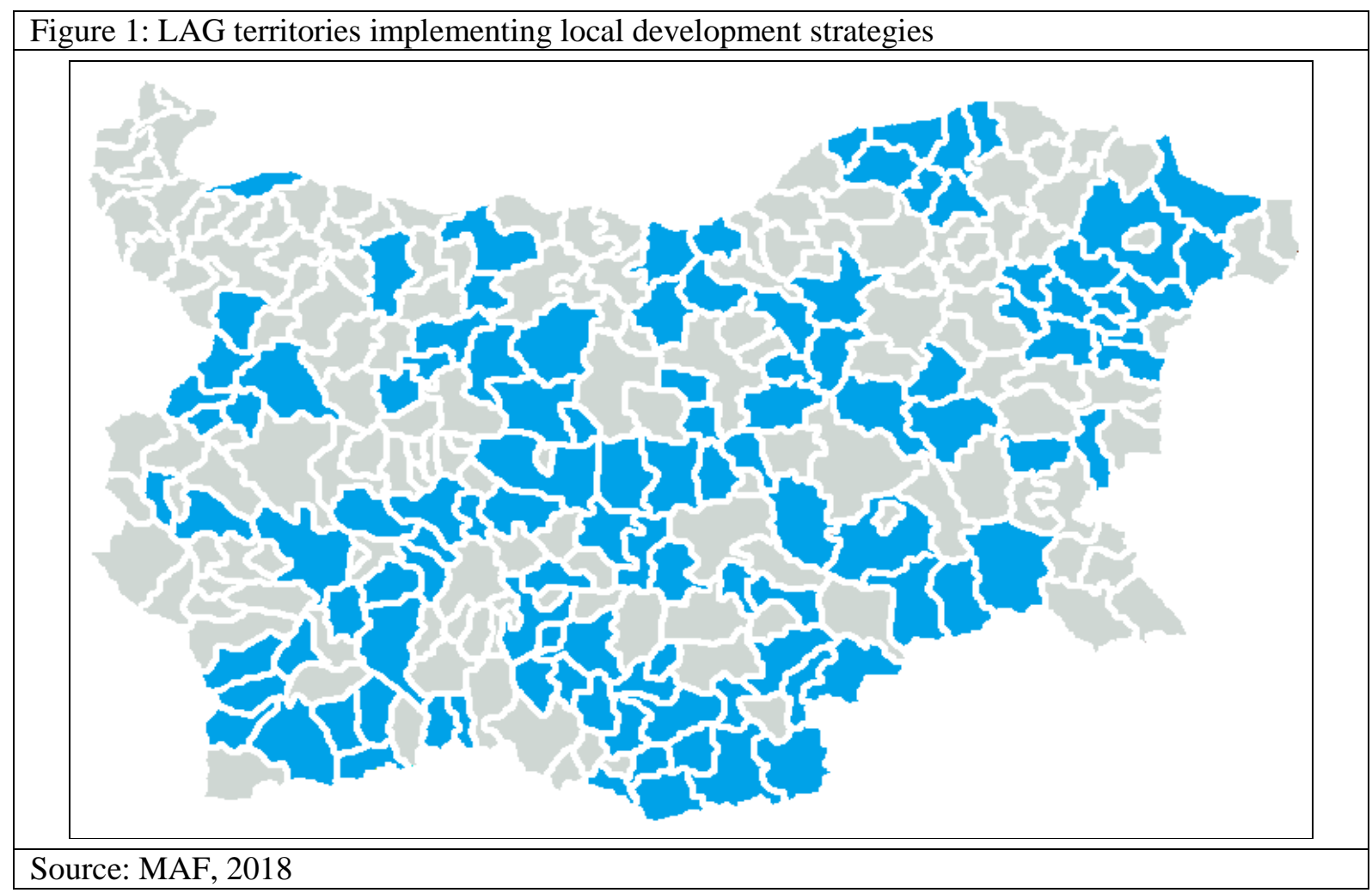

\section{Innovations in Bulgarian rural areas}

In the program period 2007-2013, 1908 project proposals were developed as part of the implementation of local development strategies. Despite the short run time for local development strategies, LAGs have been able to mobilize local communities to submit projects, and in some cases the total amount of projects submitted exceeds the budget available for projects by 208.96\% (LAG Breznik-Tran). According to information provided by the Ministry of Agriculture and Forestry, project proposals amount to $140 \%$ of the approved budget under measure 41 . After the final evaluation of the committees from the SFA - PA the approved projects are in total - 1 588. The beneficiaries until the signing of contract were 1221 . The total subsidy paid out for the implemented projects amounts to $99 \%$ of the updated budget under measure 41 and the number of projects implemented was 1170 . The LAG projects have created a total of 2609 new jobs, of which $38.25 \%$ are within agricultural holdings and $61.75 \%$ are of non-agricultural activities. 19.7\% of created jobs are directed towards people under 25 years old. Despite the described above positives of the approach, the contribution of the RDP 2007-2013 to the introduction of innovative approaches is generally assessed as negligible (Evaluation of LEADER/CLLD, 2017). All measures supporting the implementation of innovative approaches and technologies, except one measure, do not achieve their target values. The indicator for the number of farms that have implemented new products and/or new technologies under Axis 1 were $36 \%$. The main measure aimed towards the cooperation and development of new products, processes and technologies is not even launched and implemented. In business projects, beneficiaries preferred modernization and technological improvements according to the introduction of new technologies.

The LEADER approach's main contribution for facilitating innovation is measure 421, which is intended to support joint activities, and to support rural innovation in products and services that combine different rural features and create added value for rural areas, as well as supporting the creation of an EU-level identity in addition to thr local, regional and national identity. There is only limited interest in the measure due to the delayed start-up and the insufficient amount of time for implementation of the projects. Only 9 projects with beneficiaries of 15 LAGs have been implemented. As a result, 3 innovative products have been implemented. 
LAGs have contributed to the objectives of the local strategies of the 57 municipalities in whose territory they operate. The analysis of the set indicators shows that the number of projects financed by the LAG is $59 \%$ (1374 projects) and the number of beneficiaries financed by the LAG is $73 \%$ (997 beneficiaries). A major factor that constrains the support is the limited time for the realization of projects due to delays in the implementation of the approach.

The data of our own conducted survey shows that the contribution of the LEADER approach is meaningfully evaluated by the experts on a district level. By using a five-point assessment scale, grades 2 and 3 are most predominant, with the lower level of assessment being in Varna (2.0) and Blagoevgrad (1.5). Experts support their assessments with small funds of Axis 4, with local bias in approving projects and non-compliance with the statutory deadlines for approving projects and their funding. The highest (average 3.9) assessment came from the contribution of the local initiative groups for the preservation of cultural and intangible heritage and the activation of civil society (3.8), and the lowest averages were from job creation and the market infrastructure of farmers.

\section{Conclusion}

The LEADER and the CLLDA introduce innovative practices for Bulgarian conditions for activating local initiatives and improving local self-government. Their main contributions for improving local governance and facilitating innovation have to be interpreted in several ways:

- The establishment of LAGs as public-private partnerships and participants in different network structures of partnership in the country and the EU;

- Activating stakeholders, broadcasting leaders and improving coordination between them;

- Establishing local expertise and administrative capacities to support business organizations, local authorities and the non-governmental sector in the development and management of innovative projects;

- Achieving sustainability in the function of LAGs as part of the territories.

The factors that influence the success of the LEADER approach and its importance for rural development in each country differ in their administrative, socio-economic, historical and cultural contexts. The arguments about the importance of the territorial (national, regional, local) context for the success or failure of EU programs such as LEADER can be found in the research of Europeanization processes in Central and Eastern Europe. Underlining the importance of the location and context in which EU specific approaches, rules and regulations are implemented, some authors stress that EU programs often do not fit into the local environment and peoples' life styles, but still society is forced to change and try to adapt to the new conditions in their daily lives (Knudsen, 2012). In this point of view, Bulgarian LAGs continue to implement the CLLDA in the process of adapting to the specific conditions of rural areas.

\section{Acknowledgements}

The research leading to these results received funding from the Bulgarian Science Fund - project:w "Sustainable multifunctional rural areas: rethinking agricultural models and systems with increased requirements and limited resources" (2017-2020). There will be a change in both the impact of agriculture on rural development and its role for the development of the regions.

\section{References}

Aldorfai, G., Czabadai, L., Topa, Z. (2016). An Innovative Methodology for Supporting the CLLD. Polish Journal of Management Studies, Vol. 13 (1), pp. 7-17. https://doi.org/10.17512/pjms.2016.13.1.01

Bumbalová, M., Takáč, I., Tvrdoňová, J., Valach, M. (2016). Leader - Are Stakeholders in Slovakia Ready for Communityled Local Development? Case Study Findings. European Countryside, Vol. 2, pp. 160-174. https://doi.org/10.1515/euco2016-0013.

Dax, T. \& Oedl-Wieser, T. (2016). Rural innovation activities as a means for changing development perspectives - An assessment of more than two decades of promoting LEADER initiatives across the European Union. Studies in Agricultural Economics, Vol. 118, pp. 30-37. DOI: https://doi.org/10.7896/j.1535.

Dax, T., Strahl, W., Kirwan, J. \& Maye, D. (2016). The Leader programme 2007-2013: Enabling or disabling social innovation and neo- endogenous development? Insights from Austria and Ireland. European Urban and Regional Studies, Vol. 23 (1), pp. 56-68. https://doi.org/10.1177/0969776413490425.

Doitchinova, J., Miteva, A. \& Stoyanova, Z. (2012). The process of creating local action groups in Bulgaria- problems and prospects, Scientific Annals of the "Alexandru Ioan Cuza" University of Iasi , Economic Sciences Section, Vol. 59, No 2, p.183-208. 
Doitchinova, J., O`Shaughnessy, M., Galdeano, E. (2015). The Contribution of the LEADER Programme to Sustainable Rural Development - The Cases of Ireland, Spain and Bulgaria, Vision 4 a Cooperative Future \& Cooperativism for 21st Century Europe \& Beyond'(Selected Papers - 4-6 December, 2014, Bratislava, Slovakia), pp. 52-59. ISSN 978-954305-3988, Kota Publishing Company, Stara Zagora.

Doitchinova, J., Stoyanova, Z. (2014). Activation of local communities for development of rural areas, Economics of Agriculture, Belgrade, Vol. 61, Number 3, July-September 2014, p.661-675.

Doitchinova, J., Zaimova, D. (2015). Innovative rural development through networks and partnerships, Trakia Journal of Sciences, Vol. 13, Suppl. 1, pp 282-293.

EC. (2005). Council Regulation (EC) No 1698/2005 of 20 September 2005 on support for rural development by the European Agricultural Fund for Rural Development(EAFRD).

European Commission. (2014). Community-Led Local Development.

Evaluation of LEADER/CLLD. (2017). The European Evaluation Helpdesk for Rural Development. Available at https://enrd.ec.europa.eu/evaluation/publications/evaluation-leaderclld_en (Accessed on 08/11/2017).

Hall, A., Yoganand, B., Sulaiman, V., Clark, N. (2004). Postharvest innovations in innovations: a synthesis of recent cases. In Innovations in innovations: reflections on partnership, institutions and learning, ed. A. Hall, B. Yoganand, V.R. Sulaiman, R.S. Raina, C.S. Prasad, G.C. Naik, and N. Clark, 29-50.

Kis, K., Gil, J., Veha, A. (2012). Effectiveness, Efficiency and Sustainability in Local Rural Development Partnerships. Applied Studies in Agribusiness and Commerce, Vol. 6 (3-4), pp. 31-38. https://doi.org/10.19041/Apstract/2012/3-4/4

Knudsen, I. (2012). New Lithuania in Old Hands: Effects and Outcomes of Euro- peanization in Rural Lithuania. Anthem Press, London.

MAF. (2018).Ex-post evaluation of the Rural Development Program 2007-2013. Final Report.

Mahroum, S., Atterton, J., Ward, N., Willams, A., Naylor, R.,Hindle,R., Rowe F. (2007). Rural Innovation, NESTA.

Miller, S. (2014). Emerging Trends and Challenges in Community - Led Local Development (CLLD). European Structural and Investment Funds Journal, Vol. 2(4), pp. 302-307.

Pike, A., Rodriguez-Pose, A., Tomaney, J. (2007). Local and Regional Development.London: Routledge, 2006. Ray Hudson Journal of Economic Geography, Vol. 7 (2), pp. 217-219. https://doi.org/10.1093/jeg/lbl026.

Prits, M., Aro, K. (2016). Experience of designing development strategies for areas of activity in Estonia using the example of three non-governmental organisations. Proceedings of the 2016 International Conference "Economic Science for Rural Development”, No 42, pp. 140-144, Jelgava, LLU ESAF, 21-22 April 2016.

Svobodová, H. (2015). Do The Czech Local Action Groups Respect The Leader Method? Acta Universitatis Agriculturae et Silviculturae Mendelianae Brunensis, Vol. 63 (5), pp. 1769-1777. https://doi.org/10.11118/actaun201563051769. 